\title{
Effects of Racing Surface and Turn Radius on Fatal Limb Fractures in Thoroughbred Racehorses
}

\author{
Michael Peterson 1,*, Wayne Sanderson ${ }^{1}$, Nurlan Kussainov ${ }^{1}$, Sarah Jane Hobbs ${ }^{2}$, Patti Miles ${ }^{3}$, Mary C. Scollay 4 \\ and Hilary M. Clayton 5 iD \\ 1 Biosystems and Agricultural Engineering and UK Ag Equine Programs, University of Kentucky, Lexington, \\ KY 40546, USA; wayne.sanderson@uky.edu (W.S.); nbku222@g.uky.edu (N.K.) \\ 2 Centre for Applied Sport and Exercise Sciences, University of Central Lancashire, Preston, \\ Lancashire PR1 2HE, UK; SJHobbs1@uclan.ac.uk \\ 3 Maine Business School, University of Maine, Orono, ME 04469, USA; patti.miles@maine.edu \\ 4 Racing Medication and Testing Consortium, Lexington, KY 40507, USA; mcscollay@rmtcnet.com \\ 5 Sport Horse Science, Mason, MI 48854, USA; claytonh@msu.edu \\ * Correspondence: mick.peterson@uky.edu
}

check for

updates

Citation: Peterson, M.; Sanderson,

W.; Kussainov, N.; Hobbs, S.J.; Miles, P.; Scollay, M.C.; Clayton, H.M.

Effects of Racing Surface and Turn Radius on Fatal Limb Fractures in Thoroughbred Racehorses.

Sustainability 2021, 13, 539 .

https://doi.org/10.3390/su13020539

Received: 19 December 2020

Accepted: 5 January 2021

Published: 8 January 2021

Publisher's Note: MDPI stays neutral with regard to jurisdictional clai$\mathrm{ms}$ in published maps and institutional affiliations.

Copyright: (C) 2021 by the authors. Licensee MDPI, Basel, Switzerland. This article is an open access article distributed under the terms and conditions of the Creative Commons Attribution (CC BY) license (https:// creativecommons.org/licenses/by/ $4.0 /)$.

\begin{abstract}
North American Thoroughbred racing is conducted on three types of surfaces-dirt, turf, and synthetic. The tracks are oval, and races are run counterclockwise. The loading on right and left limbs is expected to differ as a function of turn radius, banking, surface, and gait asymmetry. Hind limbs and forelimbs also have different functions related to propulsion and turning, respectively. This study uses the Equine Injury Database for race starts from 1 January 2009 through 31 December 2014, to compare injury rates across participating North American racetracks. The data are limited to catastrophic injuries in which horses died or were euthanized due to a fracture within $72 \mathrm{~h}$ of the start of the race. Overall injury rates were lower on turf and synthetic surfaces and the pattern of limb injuries in left vs. right and fore vs. hind limbs were different. Regardless of surface, forelimbs were more likely to fracture. Dirt surfaces showed higher rates of forelimb injuries compared to other surfaces, hind limbs were more likely to experience a fatal fracture on turf than on dirt. The left fore and right hind limbs were more likely to experience a fatal fracture but only on dirt surfaces.
\end{abstract}

Keywords: Thoroughbred; musculoskeletal; racetrack; turning; laterality

\section{Introduction}

In North America, Thoroughbred races are run counterclockwise on oval tracks with a perimeter ranging from 1200 to $2000 \mathrm{~m}$. There is considerable variability across the country with regard to racetrack design and geometry, the nature of the track surface, the length of the races and the proportion of race time spent traveling straight vs. turning. All of these factors contribute to the risk of injury and risk of injury, both fatal and non-fatal, but the variability across tracks makes it difficult to determine the relative importance of the different variables. This study addresses the effects of surface type and turn radius on the relative risk of fractures in the left and right, fore- and hind limbs.

Thoroughbred racetracks are surfaced with one of three types of surface materials known as turf, dirt and synthetic. Dirt surfaces typically contain 80-95\% sand and 5-20\% clay and silt $[1,2]$. Synthetic surfaces are a combination of well-sorted quartz sand (sand with primarily quartz minerals and with a narrow distribution of grain sizes), fiber, and wax [3]. Turf surfaces have been less comprehensively characterized but may be either cool weather species such as bluegrass or fescue or in warmer climates bermudagrass, grown on native soil or a sand turf profile.

Races are run over a range of distances from "sprints races" run around one half of the oval to "route races" that are typically run around the entire oval. However, race distance and the amount of time spent negotiating the turns are only loosely related. At some tracks, 
horses can race $1600 \mathrm{~m}$ with only one turn of 180 degrees, whereas at most tracks races longer than $1400 \mathrm{~m}$ are run around the full oval with two 180 degree turns.

The radius of the turns and the amount of banking through the turns are not standardized. Turns are typically banked by $2-6 \%$ and the straights have a $1-2 \%$ crossfall (gradient or slope across the track toward the inside rail) to facilitate drainage. Drainage is primarily horizontal on dirt tracks. Some synthetic tracks do not have any crossfall in the straights since water is able to drain vertically. Most North American turf courses are oval tracks located inside a dirt or synthetic oval. Therefore, the turn radius is smaller for turf tracks and generally lies within a smaller range than for dirt tracks. Synthetic tracks are more expensive to install than dirt or turf, so most are located at larger racetracks where the turn radius tends to be larger with less variation between tracks. At the other end of the spectrum, a majority of smaller racetracks have a single surface which is usually dirt and, in the absence of an inner turf track, the turn radius can be as small as $50 \mathrm{~m}$ which is advantageous because the track occupies less space.

Thoroughbreds race at a gallop, which is an inherently asymmetrical gait implying unequal forces and kinematics in the trailing and leading limbs [4]. While the vertical loading is similar in fore- and hind limbs, the hind limbs provide the primary tractive effort [5]. Turning imposes additional asymmetrical forces on the limbs on the inside and outside of the turn [6]. Thoroughbreds negotiate the counterclockwise turns on the left lead to maintain balance [7] and change to the right lead in the straightaways [8] to reduce muscular fatigue. The combination of an asymmetrical gait and always racing counterclockwise suggests that the frequency of injuries may differ between the left and right limbs. However current evidence is inconclusive regarding the frequency of left and right limb injuries $[9,10]$.

Horses turn by generating an inwardly-directed centripetal force that is mathematically explained as the product of horse mass and velocity squared divided by turn radius [6]. Since radius of curvature of the turns influences the amount of force that must be generated at the ground, the variation observed in turn radii, particularly dirt surfaces, affects limb loading. To be successful, racehorses must lean into the turn so their center of mass is inward of the position of their hooves on the ground (Figure 1). This assists in developing the necessary centripetal force to negotiate the turn, balances the moments that tend to rotate the horse outwards, and aligns the resultant force vector more closely with the long axis of the limb [11]. The importance of proper track design in reducing peak limb loading and injuries is well known in Standardbred horses [12,13], but these results should be applied to Thoroughbred racing with caution because of the fundamental differences between the inherently symmetrical trotting gait of the Standardbred horse and the asymmetrical gallop of the Thoroughbred. The fact that Thoroughbreds in North America always race counterclockwise, lean to the left in the turns, and have an asymmetrical gait contribute to the unequal load distribution between contralateral limbs, which would be expected to create an unequal distribution of injuries in the left and right limbs.

Studies related to the dynamics of turning at a gallop [14] have shown that horses slow their speed for a turn due to either the inability to produce sufficient force or having insufficient frictional resistance at the hoof-shoe-surface interface. A limb's ability to generate force during the stance phase is thought to limit turning performance in humans [15,16], since the sum of the vertical, turning and propulsive forces cannot exceed the maximal force that the musculoskeletal system is capable of producing $\left(F_{\text {resultant }}\right.$ in Figure 1$)$. However, the potential also exists for inadequate surface traction to limit an animal's turning speed, particularly on smaller radius turns or if the banking is insufficient. When the horse and rider lean inwards and shift their combined center of mass toward the inside of the turn, the surface must be able to support the angulated hoof with the resulting transverse loading ( $F_{\text {transverse }}$ in Figure 1$)$. Deformable surfaces such as fiber sand require a smaller frictional force to make the turn compared to a non-deformable surface, such as asphalt [17]. All three types of racing surfaces are somewhat deformable with synthetic showing the lowest deformation but comparable to fiber sand. Consequently, turning mechanics and limb 
loading are also dependent on surface characteristics. Thus, the relationship between turn radius, surface type and the rate of injuries in each of the horse's limbs provides insight into the etiology of musculoskeletal disease and the potential value of design modifications to reduce injuries.

A

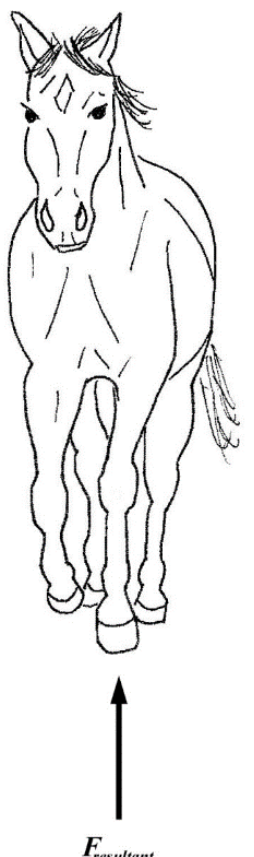

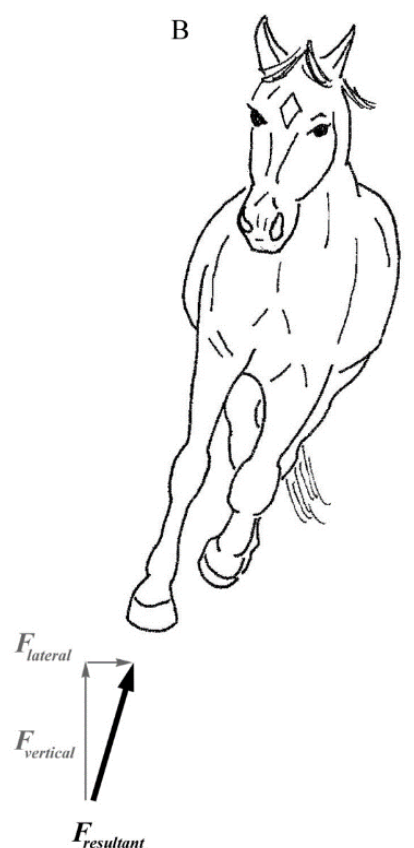

Figure 1. Direction of the resultant ground reaction force $\left(F_{\text {resultant }}\right)$. (A) With the horse's body vertically oriented on a straight, level surface, the resultant force is vertically directed. (B) During turning the horse leans inward (in this case to the horse's left) and shifts the center of mass toward the inside of the turn. This results in the generation of a transverse (centripetal) force directed toward the center of the turn which can assist in balancing the loading of the left and right limbs.

At the Welfare and Safety of the Racehorse Summit in 2008, the Equine Injury Database (EID) was established. The focus of this database is equine fatalities occurring during a race or resulting in euthanasia within $72 \mathrm{~h}$ because of race-related injuries as reported by veterinary officials. Prior to the inception of the EID, rates of fatalities in North American flat racing were reported to range from 1.1 and 1.8 per 1000 starts [18-20]. The EID data have provided a systematic way of looking at overall injury rates and can also partition out musculoskeletal injury rates. This offers the possibility of investigating the roles of a wide range of race- and horse-related factors [21]. Although physical properties of the track, including turn geometry and banking, have been cited as important factors in the etiology of injuries $[9,22,23]$, epidemiological studies describing the risks of specific aspects of racetrack design for Thoroughbred racing are lacking.

The aims of this study were to use the EID data to investigate differences in the prevalence of catastrophic musculoskeletal injuries in the left and right limbs in relation to surface type and turn radius. This information has the potential to make racing safer for horses and jockeys by providing direction for the development of new surface materials and adaptations in track design.

\section{Materials and Methods}

The present research uses the EID and Equibase data to seek associations between fatal limb fractures and factors related to the horse, the race and the track for the years 2009 through 2014. Since the EID data are used, fatalities are defined as events occurring on the racetrack which result in death or euthanasia within $72 \mathrm{~h}$ of the race [21]. The causes of death are broadly divided into fractures, soft tissue injuries and sudden deaths. The 
findings described here are limited to fractures involving one or more limbs that resulted in death or euthanasia within $72 \mathrm{~h}$ of the race. Equine fatalities that are related to racing accidents are also excluded. Accidents incur injuries which are primarily a consequence of an external event such as clipped heals, interference from other horses, or trauma as opposed to a musculoskeletal failure such as sesamoid bone or metacapral fracture..

Commercial measurement tools were used with satellite data to measure the radius of each of the tracks (Google Earth, Mountain View, CA, USA). Synthetic tracks had only a small range of radii $(120-160 \mathrm{~m})$. Turf tracks had a larger range of radii $(50-160 \mathrm{~m})$ but only about $15 \%$ of starts occurred on tracks with a radius greater than $130 \mathrm{~m}$. Moreover, when races are held on turf tracks the position of the inside rail is moved between race days causing the radius of the turns to change by as much as $10 \mathrm{~m}$. Only the dirt tracks had a sufficiently large and well-distributed range in track radii $(50-195 \mathrm{~m})$ for inclusion in the analysis of the effects of turning radius. Using the distribution of turn radii, the dirt tracks were divided into approximate quartiles with about $25 \%( \pm 3 \%)$ of the total number of horse starts in each category. On race day turf and dirt tracks were classified as good or off based on the subjective evaluation included in the Equibase data.

The denominator unit of analysis was EID tracked race starts in North America during the years 2009-2014. The incidence and relative risk of fatal limb fractures in association with horse, race, and track characteristics, together with corresponding 95\% confidence limits and p-values, were calculated using SAS v9.6 (SAS Institute, Inc., Cary, NC, USA). The numbers of fatal limb injuries per race were low, consequently Poisson regression, a generalized linear method with a link function, was used to calculate relative risk ratio by multiple covariates. The selected reference categories were typically the categories with the lowest expected incidence rate. Respective associations of fatality by risk factor were initially assessed using univariate analyses. Analyses of limb injury rates were stratified by track surface and track turning radius.

\section{Results}

From 2009 to 2014 the EID included 2,356,427 race starts, 75.4\% of which were run on dirt, $13.2 \%$ on turf and $11.4 \%$ on synthetic surfaces. There were 3954 race-related fatalities associated with fractures of one or more limbs. The number of fractures, fatality rate and risk ratios for factors related to horse, race conditions and track/surface are shown in Tables $1-3$, respectively.

Table 1. Incidence of fatal limb fractures by horse-related factors in Thoroughbred racehorses competing in flat racing in the United States and Canada 2009-2014. The risk ratios are calculated by comparing the fatality proportions in the categories of each factor to the fatality proportion of the category marked as Ref (for reference category).

\begin{tabular}{|c|c|c|c|c|c|}
\hline & \# Fatalities per \# Starts & Fatality Rate per 1000 Starts & Risk Ratio & $95 \% \mathrm{CI}$ & $p$-Value \\
\hline All Starts & $3954 / 2,356,427$ & 1.678 & & & \\
\hline \multicolumn{6}{|c|}{ Gender of Horse } \\
\hline Mare & $1574 / 1,024,002$ & 1.537 & Ref & - & - \\
\hline Gelding & $1730 / 1,042,102$ & 1.660 & 1.08 & $1.01-1.16$ & 0.027 \\
\hline Stallion & $650 / 290,323$ & 2.239 & 1.46 & $1.33-1.60$ & $<0.001$ \\
\hline \multicolumn{6}{|l|}{ Age in Years } \\
\hline$\leq 3$ & $1389 / 853,445$ & 1.628 & Ref & - & - \\
\hline $4-5$ & $1888 / 1,061,462$ & 1.779 & 1.09 & $1.02-1.17$ & 0.012 \\
\hline$\geq 6$ & $677 / 441,520$ & 1.533 & 0.94 & $0.86-1.03$ & 0.202 \\
\hline \multicolumn{6}{|c|}{ Weight Carried } \\
\hline$\leq 52 \mathrm{~kg}$ & $445 / 206,207$ & 2.158 & Ref & - & - \\
\hline$>52-54 \mathrm{~kg}$ & $2114 / 1,288,614$ & 1.641 & 0.76 & $0.69-0.84$ & $<0.001$ \\
\hline$>54-56 \mathrm{~kg}$ & $1373 / 836,163$ & 1.642 & 0.76 & $0.68-0.85$ & $<0.001$ \\
\hline$>56 \mathrm{~kg}$ & $22 / 25,443$ & 0.865 & 0.40 & $0.26-0.61$ & $<0.001$ \\
\hline
\end{tabular}


Table 2. Incidence of fatal limb fractures by race-related factors in Thoroughbred racehorses competing in flat racing in the United States and Canada 2009-2014. The risk ratios are calculated by comparing the fatality proportions in the categories of each factor to the fatality proportion of the category marked as Ref (for reference category).

\begin{tabular}{|c|c|c|c|c|c|}
\hline & $\begin{array}{c}\text { \# Fatalities per } \\
\text { \# Starts }\end{array}$ & $\begin{array}{l}\text { Fatality Rate per } \\
1000 \text { Starts }\end{array}$ & Risk Ratio & $95 \%$ CI & $p$-Value \\
\hline All Starts & $3954 / 2,356,427$ & 1.678 & & & \\
\hline \multicolumn{6}{|l|}{ Year } \\
\hline 2009 & $744 / 444,760$ & 1.673 & Ref & - & - \\
\hline 2010 & $663 / 415,889$ & 1.594 & 0.95 & $0.86-1.06$ & 0.367 \\
\hline 2011 & $685 / 399,058$ & 1.717 & 1.03 & $0.93-1.14$ & 0.626 \\
\hline 2012 & $668 / 388,306$ & 1.720 & 1.03 & $0.93-1.14$ & 0.599 \\
\hline 2013 & $634 / 366,211$ & 1.731 & 1.03 & $0.93-1.15$ & 0.525 \\
\hline 2014 & $560 / 342,203$ & 1.636 & 0.98 & $0.88-1.09$ & 0.694 \\
\hline \multicolumn{6}{|l|}{ Race Distance } \\
\hline$\leq 1408$ m (7 Furlongs) & $2679 / 1,525,963$ & 1.756 & Ref & - & - \\
\hline >1408 m (7 Furlongs) & $1275 / 830,464$ & 1.535 & 0.87 & $0.82-0.93$ & $<0.001$ \\
\hline \multicolumn{6}{|l|}{ Field Size } \\
\hline $2-6$ & $630 / 393,229$ & 1.602 & Ref & - & - \\
\hline $7-10$ & $2767 / 1,617,842$ & 1.710 & 1.07 & $0.98-1.16$ & 0.138 \\
\hline $11-20$ & $557 / 345,356$ & 1.613 & 1.01 & $0.90-1.13$ & 0.909 \\
\hline \multicolumn{6}{|l|}{ Post Position } \\
\hline $1-2$ & $953 / 589,246$ & 1.617 & Ref & - & - \\
\hline $2-4$ & $994 / 588,755$ & 1.688 & 1.04 & $0.96-1.14$ & 0.343 \\
\hline $5-6$ & $947 / 562,653$ & 1.683 & 1.04 & $0.95-1.14$ & 0.385 \\
\hline $7-20$ & $1060 / 615,773$ & 1.721 & 1.06 & $0.98-1.16$ & 0.162 \\
\hline \multicolumn{6}{|l|}{ Sex Restriction } \\
\hline No & $2387 / 1,341,240$ & 1.780 & Ref & - & - \\
\hline Yes & $1567 / 1,015,187$ & 1.544 & 0.87 & $0.81-0.92$ & $<0.001$ \\
\hline \multicolumn{6}{|l|}{ Purse } \\
\hline$\leq$ USD 8000 & $728 / 489,670$ & 1.487 & Ref & - & - \\
\hline$>$ USD 8000-\$30,000 & $2635 / 1,419,447$ & 1.856 & 1.25 & $1.15-1.36$ & $<0.001$ \\
\hline$>$ USD 30,000 & $591 / 447,310$ & 1.321 & 0.89 & $0.80-0.99$ & 0.033 \\
\hline
\end{tabular}

Characteristics related to the horse (Table 1) that were significantly associated with fracture risk were gender, with males having a higher injury rate than mares and stallions having a higher rate than geldings. Age was also significant with a lower injury rate for horses less than 3 years old compared to 4 and 5-year-old horses. Carrying a higher weight also reduced the fracture risk. With regard to race conditions (Table 2), races run over $>1408 \mathrm{~m}$ (seven furlongs) had lower risk than those run over shorter distances. Races in which the purse was >USD 8000-USD 30,000 had a higher risk of fracture compared to those with lower and higher purses. Sex restricted races had a lower risk than those without sex restriction. Year of race, field size and post position were not associated with risk of fatal fracture.

All track-related factors listed in Table 3 influenced fracture risk. There was a significantly higher risk ratio for fatal limb facture if the last timed workout was performed on dirt or if the stretch distance in the race was longer than $477 \mathrm{~m}$. The effect of turn radius (dirt tracks only) was evaluated using $>126-129 \mathrm{~m}$ (third quartile) as the reference. Tracks 
with turn radii in the second (>114-126 m) and fourth quartiles ( $>129 \mathrm{~m})$ had significantly higher overall rates of fatal limb fractures than those in the reference third quartile.

Table 3. Incidence of fatal limb fractures by track-related factors in Thoroughbred racehorses competing in flat racing in the United States and Canada 2009-2014. The risk ratios are calculated by comparing the fatality proportions in the categories of each factor to the fatality proportion of the category marked as Ref (for reference category).

\begin{tabular}{|c|c|c|c|c|c|}
\hline & $\begin{array}{c}\text { \# Fatalities per } \\
\text { \# Starts }\end{array}$ & $\begin{array}{l}\text { Fatality Rate per } \\
1000 \text { Starts }\end{array}$ & Risk Ratio & $95 \%$ CI & $p$-Value \\
\hline All Starts & $3954 / 2,356,427$ & 1.678 & & & \\
\hline \multicolumn{6}{|l|}{ Track Surface } \\
\hline Synthetic & $310 / 269,686$ & 1.149 & 0.64 & $0.57-0.72$ & $<0.001$ \\
\hline Turf & $468 / 311,286$ & 1.503 & 0.84 & $0.76-0.93$ & $<0.001$ \\
\hline Dirt & $3176 / 1,775,455$ & 1.789 & Ref & - & - \\
\hline \multicolumn{6}{|l|}{ Track Condition } \\
\hline Good Dirt & $2770 / 1,560,919$ & 1.775 & Ref & - & - \\
\hline Off Dirt & $356 / 190,699$ & 1.867 & 1.05 & $0.94-1.17$ & 0.368 \\
\hline Good Turf & $455 / 296,737$ & 1.533 & 0.86 & $0.78-0.95$ & 0.004 \\
\hline Off Turf & $13 / 14,549$ & 0.891 & 0.50 & $0.29-0.87$ & 0.013 \\
\hline Synthetic & $360 / 293,523$ & 1.226 & 0.69 & $0.62-0.77$ & $<0.001$ \\
\hline \multicolumn{6}{|c|}{ Last Workout Surface } \\
\hline Synthetic & $458 / 320,979$ & 1.427 & Ref & - & - \\
\hline Turf & $26 / 18,237$ & 1.426 & 0.99 & $0.67-1.48$ & 0.996 \\
\hline Dirt & $3469 / 2,015,706$ & 1.721 & 1.21 & $1.09-1.33$ & $<0.001$ \\
\hline \multicolumn{6}{|l|}{ Stretch Distance } \\
\hline$\leq 446$ yds & $1271 / 761,434$ & 1.669 & Ref & - & - \\
\hline$>446-522$ yds & $1914 / 1,174,972$ & 1.629 & 0.98 & $0.91-1.05$ & 0.500 \\
\hline$>522 \mathrm{yds}$ & $769 / 420,021$ & 1.831 & 1.10 & $1.00-1.20$ & 0.043 \\
\hline
\end{tabular}

A number of horses fractured multiple limbs, so the total number of cases is not equal to the sum of the reported fractures per limb. The total number of fractures per limb or multiple limbs are separated by track radius for the dirt tracks in Table 4. Compared with track radii in the range of $>126-129 \mathrm{~m}$, there was a significantly greater risk of right forelimb fractures for the two shorter turn radius categories (first and second quartiles), while right hind and multiple limb fractures had significantly higher risk ratios for turn radii $>129 \mathrm{~m}$. When the data were separated by limb, it became clear that the right forelimb was at higher risk of fracture on tighter turn radii $(<126 \mathrm{~m})$ whereas the right hind limb appeared more susceptible to fractures on larger turn radii $(>129 \mathrm{~m})$.

With regard to surface type, risk ratio was lower for synthetic and turf surfaces compared with dirt (Table 3). Data for track condition showed that risk ratio for dirt tracks did not differ between ratings of good or off but both of these had higher risk ratios than good turf, off turf and synthetic.

When the risk of fracturing a specific limb alone or in combination with another limb(s) is broken down by surface type (Table 5), there is a clear pattern in the forelimbs with a higher risk of fracture on dirt for the left or right forelimb alone or in combination with another limb. The values for either left or right forelimb show the lowest risk of fracture on synthetic followed by turf and dirt. 
Table 4. Fatal limb fractures for all limbs combined, for individual limbs and for multiple limbs by turn radius. Values for track radius are based on dirt tracks only.

\begin{tabular}{|c|c|c|c|c|c|}
\hline & \multicolumn{5}{|c|}{ Track Radius-Dirt Tracks Only } \\
\hline & $>50-114 \mathrm{~m}$ & $>114-126 \mathrm{~m}$ & $>126-129 \mathrm{~m}$ & $>129 \mathrm{~m}$ & Total \\
\hline $\begin{array}{c}\text { Number Horse Starts } \\
(\%)\end{array}$ & $\begin{array}{l}471,126 \\
(26.5)\end{array}$ & $\begin{array}{c}497,847 \\
(28.1)\end{array}$ & $\begin{array}{c}396,371 \\
(22.3)\end{array}$ & $\begin{array}{c}409,136 \\
(23.1)\end{array}$ & $1,775,455$ \\
\hline \multicolumn{6}{|l|}{ All Fatalities } \\
\hline Number & 835 & 924 & 652 & 763 & 3176 \\
\hline Incidence per 1000 race starts & 1.772 & 1.856 & 1.645 & 1.865 & 1.789 \\
\hline Risk Ratio ( $p$-value) & $1.08(0.153)$ & $1.13(0.018)$ & 1.00 & $1.13(0.019)$ & \\
\hline \multicolumn{6}{|l|}{ Left Fore } \\
\hline Number & 397 & 507 & 355 & 392 & 1652 \\
\hline Incidence per 1000 Race Starts & 0.844 & 1.019 & 0.896 & 0.959 & 0.930 \\
\hline Risk Ratio ( $p$-value) & $0.94(0.405)$ & $1.14(0.063)$ & 1.00 & $1.07(0.356)$ & \\
\hline \multicolumn{6}{|l|}{ Right Fore } \\
\hline Number & 411 & 426 & 293 & 323 & 1454 \\
\hline Incidence per 1000 Race Starts & 0.873 & 0.857 & 0.740 & 0.790 & 0.819 \\
\hline Risk Ratio ( $p$-value) & $1.18(0.030)$ & $1.16(0.05)$ & 1.00 & $1.07(0.414)$ & \\
\hline \multicolumn{6}{|l|}{ Left Hind } \\
\hline Number & 36 & 38 & 18 & 26 & 118 \\
\hline Incidence per 1000 Race Starts & 0.077 & 0.076 & 0.045 & 0.064 & 0.067 \\
\hline Risk Ratio ( $p$-value) & $1.68(0.071)$ & $1.68(0.070)$ & 1.00 & $1.40(0.273)$ & \\
\hline \multicolumn{6}{|l|}{ Right Hind } \\
\hline Number & 42 & 40 & 21 & 50 & 153 \\
\hline Incidence per 1000 Race Starts & 0.089 & 0.080 & 0.053 & 0.122 & 0.086 \\
\hline Risk Ratio ( $p$-value) & $1.68(0.514)$ & $1.52(0.122)$ & 1.00 & $2.31(0.001)$ & \\
\hline \multicolumn{6}{|l|}{ Multiple Limb Injuries } \\
\hline Number & 70 & 83 & 51 & 34 & 238 \\
\hline Incidence per 1000 Race Starts & 0.149 & 0.167 & 0.129 & 0.083 & 0.134 \\
\hline Risk Ratio ( $p$-value) & $1.15(0.433)$ & $1.30(0.145)$ & 1.00 & $0.65(<0.048)$ & \\
\hline \multicolumn{6}{|c|}{ Comparison Left Fore to Right Fore } \\
\hline Left Fore Incidence & 0.844 & 1.019 & 0.896 & 0.959 & 0.930 \\
\hline Right Fore Incidence & 0.893 & 0.857 & 0.740 & 0.790 & 0.819 \\
\hline Risk Ratio ( $p$-value) & $0.96(0.623)$ & $1.19(0.008)$ & $1.21(0.015)$ & $1.21(0.010)$ & $1.14(<0.001)$ \\
\hline \multicolumn{6}{|c|}{ Comparison Left Hind to Right Hind } \\
\hline Left Hind Incidence & 0.077 & 0.076 & 0.045 & 0.064 & 0.067 \\
\hline Right Hind Incidence & 0.089 & 0.080 & 0.053 & 0.122 & 0.086 \\
\hline Risk Ratio ( $p$-value) & $0.86(0.497)$ & $0.95(0.821)$ & $0.86(0.631)$ & $0.52(0.007)$ & $0.77(0.034)$ \\
\hline
\end{tabular}


Table 5. Fatal limb fractures for single or multiple limbs by track surface. The Risk Ratios (RISK RATIO) are calculated by comparing the fatal limb fracture proportions to the fatal limb fracture proportions on dirt track surfaces.

\begin{tabular}{|c|c|c|c|c|}
\hline & \multicolumn{3}{|c|}{ Track Surface } & \multirow[b]{2}{*}{ Total } \\
\hline & Synthetic & Turf & Dirt & \\
\hline Number Horse Starts (\%) & $269,527(11.4)$ & $311,043(13.2)$ & $1,773,931(75.3)$ & $2,354,501$ \\
\hline \multicolumn{5}{|l|}{ Left Fore } \\
\hline Number & 151 & 225 & 1652 & 2028 \\
\hline Incidence per 1000 Starts & 0.560 & 0.723 & 0.931 & 0.861 \\
\hline Risk Ratio ( $p$-value) & $0.60(<0.001)$ & $0.77(<0.001)$ & 1.00 & \\
\hline \multicolumn{5}{|l|}{ Only Left Fore } \\
\hline Number & 124 & 197 & 1492 & 1813 \\
\hline Incidence per 1000 Starts & 0.460 & 0.633 & 0.841 & 0.769 \\
\hline Risk Ratio ( $p$-value) & $0.55(<0.001)$ & $0.75(<0.001)$ & 1.00 & \\
\hline \multicolumn{5}{|l|}{ Right Fore } \\
\hline Number & 145 & 211 & 1454 & 1810 \\
\hline Incidence & 0.538 & 0.678 & 0.820 & 0.768 \\
\hline Risk Ratio ( $p$-value) & $0.66(<0.001)$ & $0.83(0.010)$ & 1.00 & \\
\hline \multicolumn{5}{|l|}{ Only Right Fore } \\
\hline Number & 119 & 183 & 1301 & 1603 \\
\hline Incidence & 0.442 & 0.588 & 0.734 & 0.680 \\
\hline Risk Ratio ( $p$-value) & $0.60(<0.001)$ & $0.80(0.005)$ & 1.00 & \\
\hline \multicolumn{5}{|l|}{ Either Left or Right Fore } \\
\hline Number & 504 & 682 & 4374 & 5560 \\
\hline Incidence & 1.869 & 2.191 & 2.464 & 2.361 \\
\hline Risk Ratio ( $p$-value) & $0.76(<0.001)$ & $0.89(0.004)$ & 1.00 & \\
\hline \multicolumn{5}{|l|}{ Left Hind } \\
\hline Number & 23 & 36 & 118 & 177 \\
\hline Incidence & 0.085 & 0.116 & 0.067 & 0.075 \\
\hline Risk Ratio ( $p$-value) & $1.28(0.0275)$ & $1.74(0.004)$ & 1.00 & \\
\hline \multicolumn{5}{|l|}{ Only Left Hind } \\
\hline Number & 13 & 26 & 86 & 125 \\
\hline Incidence & 0.048 & 0.084 & 0.049 & 0.053 \\
\hline Risk Ratio ( $p$-value) & $0.99(0.985)$ & $1.72(0.015)$ & 1.00 & \\
\hline \multicolumn{5}{|l|}{ Right Hind } \\
\hline Number & 28 & 35 & 153 & 216 \\
\hline Incidence & 0.104 & 0.113 & 0.086 & 0.092 \\
\hline Risk Ratio ( $p$-value) & $1.20(0.366)$ & $1.30(0.157)$ & 1.00 & \\
\hline \multicolumn{5}{|l|}{ Only Right Hind } \\
\hline Number & 19 & 26 & 124 & 169 \\
\hline Incidence & 0.071 & 0.084 & 0.070 & 0.072 \\
\hline Risk Ratio ( $p$-value) & $1.01(0.974)$ & $1.19(0.409)$ & 1.00 & \\
\hline
\end{tabular}


Table 5. Cont.

\begin{tabular}{ccccc}
\hline & & Track Surface & Dirt & Total \\
\hline Either Left or Right Hind & Synthetic & Turf & 318 & 466 \\
\hline Number & 57 & 0.293 & 0.179 & 1.00 \\
\hline Incidence & 0.212 & $1.63(<0.001)$ & & \\
\hline Risk Ratio $(p$-value $)$ & $1.18(0.252)$ & & 238 & \\
\hline Multiple Limb Injuries & & 51 & 0.134 & 0.144 \\
\hline Number & 50 & 0.164 & 1.00 & \\
\hline Incidence & 0.186 & $1.22(0.194)$ & \\
\hline
\end{tabular}

Although the overall incidence of fracture in the hind limbs is much lower than in the forelimbs, the pattern on the different types of surfaces is less clear. The risk of fatal fracture of the left hind limb only is lower on dirt than on turf, while for the left hind limb in combination with other limbs the risk is lower on dirt than synthetic. For the right hind alone or in combination with other limbs, there were no significant differences in risk ratio due to surface type. The risk of fatal fracture in either left or right hind limb is higher on turf than dirt while the risk ratio for multiple limb fractures is higher on synthetic than dirt.

Comparisons between contralateral limb pairs (Table 6) show that the risk ratio for fatal fracture is higher in the left than the right forelimb on each surface individually and on all surfaces combined. In the hind limbs, the risk is greater for the right than the left hind limb on each surface individually and on all surfaces combined.

Table 6. Incidence of fatal limb fractures in each limb and comparison of risk ratios for contralateral and lateral limb pairs.

\begin{tabular}{|c|c|c|c|c|}
\hline & \multicolumn{3}{|c|}{ Track Surface } & \multirow[b]{2}{*}{ Total } \\
\hline & Synthetic & Turf & Dirt & \\
\hline Left Fore Incidence per 1000 Starts & 0.460 & 0.633 & 0.841 & 0.769 \\
\hline Right Fore Incidence per 1000 Starts & 0.442 & 0.588 & 0.734 & 0.680 \\
\hline Risk Ratio ( $p$-value) & $1.04(0.749)$ & $1.08(0.473)$ & $1.15(<0.001)$ & $1.13(<0.001)$ \\
\hline Left Hind Incidence per 1000 Starts & 0.048 & 0.084 & 0.049 & 0.053 \\
\hline Right Hind Incidence per 1000 Starts & 0.071 & 0.084 & 0.070 & 0.072 \\
\hline Risk Ratio ( $p$-value) & $0.68(0.292)$ & $1.00(0.999)$ & $0.69(0.009)$ & $0.74(0.011)$ \\
\hline Left Fore Incidence per 1000 Starts & 0.460 & 0.633 & 0.841 & 0.769 \\
\hline Left Hind Incidence per 1000 Starts & 0.048 & 0.084 & 0.049 & 0.053 \\
\hline Risk Ratio ( $p$-value) & $5.39(<0.001)$ & $7.57(<0.001)$ & $17.34(<0.001)$ & $14.49(<0.001)$ \\
\hline Right Fore Incidence per 1000 Starts & 0.442 & 0.588 & 0.734 & 0.680 \\
\hline Right Hind Incidence per 1000 Starts & 0.071 & 0.084 & 0.070 & 0.072 \\
\hline Risk Ratio ( $p$-value) & $6.26(<0.001)$ & $7.03(<0.001)$ & $10.49(<0.001)$ & $9.48(<0.001)$ \\
\hline
\end{tabular}

With regard to the ipsilateral limb pairs, risk ratio for the left fore is higher than for the left hind and risk ratio for the right hind is higher than for the right fore on each track individually and on all tracks combined (Table 6). 


\section{Discussion}

This study has evaluated the risk of fatal fracture during Thoroughbred races on North American tracks based on the EID over a 6-year period with a focus on the influence of factors related to the horse, the conditions of the race, and the surface and geometry of the track. More specifically, we compare risk ratios for fatal fractures in the left and right, fore- and hind limbs in relation to turn radii and surface materials. In the forelimbs, the findings clearly show that the greatest risk of fracture of the left or right forelimb alone or in combination with another limb is on dirt, followed by turf and then synthetic. In the hind limbs the results are less clear cut. The left hind, either alone or in combination with another limb, has the highest risk ratio for fatal fracture on dirt. The right hind, although it has an overall higher incidence of fracture than the left hind, shows no difference in risk ratio due to surface type. Comparisons between contralateral and ipsilateral pairs of limbs show clearly that the left fore and right hind limbs are at greater risk.

The results for fatal limb fractures presented here are consistent with prior work on the influence of horse- and race-related risk factors in North American racing [21,24]. However, different results have been presented for international racing [25] that may be related to differences in the geometry of the racecourses, the direction of racing, and the focus on shorter race meets held on turf surfaces.

Consistent with previously published statistics [21] dirt tracks had a significantly higher rate of injury than both turf tracks $(p<0.001)$ and synthetic tracks $(p<0.001)$. For the time period 2009-2014 in North America, the greatest number of race starts $(75.4 \%)$ were on dirt. Turf racing represented $13.2 \%$ of race starts with the percentage increasing over the last decade [26]. The type of surface on which the last timed workout was significant with a higher risk of fatal fracture if the last workout was performed on dirt. Due to the limited availability of turf surfaces for timed works in North America, the workout surface is primarily a comparison of dirt and synthetic. Track condition was not significant with very few races on off-turf in North America and no significance to off-dirt tracks compared to good dirt. Finally, the higher injury rate on tracks with a front stretch distance longer than $475 \mathrm{~m}$ may be related to fatigue in the final stages of the race [27].

\subsection{Horse and Race Level Variables}

Other authors have used the EID to analyze the effects of a large number of horse and race factors on risk of fatality over a 5-year period (2009-2013) [24] and on fatalities specifically related to limb fractures for a 6-year period (2009-2104) [21]. Since the data from those studies use the same database as the results presented here, similar results are expected when the same variables are explored. Some minor differences are evident between results reported here with the paper by Georgopoulos and Parkin [24] which looked at a five-year time period and included all injuries not just fatal fractures.

Gender-related differences in fracture risk are in general agreement with Georgopoulos and Parkin [21] who showed a higher odds ratio in stallions than mares and geldings combined. Our evaluation indicated, further, that geldings are at higher risk than mares. This is in agreement with the meta-analysis carried out by Hitchens et al. [25] and is likely to be related to androgenic effects. For example, Mukai et al. [28] reported that male Thoroughbreds have lower heart rates than females during canter work, suggesting that males have a higher aerobic capacity. The findings for weight carried in the race showed that higher weights reduced the risk of fatal limb fractures. This may seem counter-intuitive since the gravitational effects of carrying the weight of a rider increases peak vertical forces in all limbs at trot [29]. However, the use of weight as a handicapping tool is based on the assumption that galloping speed decreases with an increase in weight carried. This has the potential to reduce peak limb loading through lengthening stride and stance durations. Similarly, the lower risk ratio over longer race distances may be related to slower average speeds and the consequent decrease in peak limb loading. 
Horse and race related risk factors in North American racing such as claiming rules and purse values differ from international racing jurisdictions [25]. Although not elaborated on here, these factors warrant further consideration.

\subsection{Track Level Variables}

In general, track-related analysis is limited by the absence of consistent data across racing jurisdictions and an absence of objective measurements of the surface. In this data set only, a general classification of surface type is possible. Differences in fatal fractures on turf, dirt or synthetic, were statistically significant and, as in prior work, the condition of the surface, good or off dirt, was not significant [21]. These results contrast with the meta-study analysis of international racing, which included the results from Georgopoulos and Parkin [21], that found no difference between dirt, turf or synthetic track surfaces, but showed higher risk with an off-track condition compared to a good track condition [25]. Because of the broader geographical considerations, the meta-study considered a larger proportion of turf surfaces and included more variable track geometry. In many cases outside of North America only one type of surface is available, usually a turf track. When this is the case, it is not an option to move racing to an adjoining dirt or synthetic surface when the turf track is classified as being off. Therefore, the only options are to run on the off track or cancel racing. When an alternative surface is available turf races are rarely run on an off-turf surface because the resulting damage interferes with the ability to run future turf races through the longer more heavily scheduled race meets. The absence of significant differences in catastrophic injury rates between turf and synthetic surfaces in the meta-study is also important. Biomechanical risk factors such as always turning left and the effect of different surfaces on the ability of the hind limbs to generate propulsion may be important to understanding the catastrophic injury rate in North American horse racing. A tighter turn radius would be expected to result in higher turning effort in the forelimbs which are responsible for generating most of the turning forces [6], together with the likelihood of differences between the trailing and leading limbs in an inherently asymmetrical gait. The type of surface affects the amount of traction available which impacts the manner in which both fore and hind limbs are able to balance previously described limits to traction and muscular effort [14].

\subsection{Dirt Track Turn Radius}

When horses race at a gallop, they normally lead with the inside fore and hind limbs through the turns to facilitate balance $[11,30]$ then switch to the opposite (outside) lead on the straights to reduce fatigue associated with asymmetrical limb loading [7,8]. Laterality in animals is equivalent to handedness in people. In horses, laterality may affect neuromotor control of locomotion leading to a left-right difference in limb movements [31], though other authors reported limited evidence of any strong effect of laterality [32].

All North American dirt racetracks included in the EID race counterclockwise around turns of a known radius, which affords an opportunity to investigate the effects of turn radius on injury rates in specific limbs. In other countries where horses race around oval tracks, such as Latin America and Turkey, track geometry is much more variable than in North America and races are run in both clockwise and counter-clockwise directions which tends to balance the asymmetrical effects of turning in the left and right limbs. The consistency with which horses use the inside and outside leads on oval racetracks suggests turning is a factor in the frequency of fatal fractures in the left and right limbs in North American racing.

The fracture rate associated with different turn radii on dirt tracks (Table 4) indicated a significantly higher rate of fracture in the left (leading) forelimb for all three quartiles except in the tightest turn. The right (trailing) hind limb only shows a significantly higher rate of injury on the largest quartile of turns radii. The frequency of injuries to the left and right limbs may be affected both by the inherent asymmetry of the gallop gait as well as the role of the individual limbs in providing supporting, propulsive and turning forces. 
Self Davies et al. [5] find that during galloping on the straight, peak vertical force and vertical impulse do not differ between the two forelimbs. This finding suggests that the higher frequency of right vs. left forelimb injuries in horses racing on tight radius turns is an effect of turning per se. Tan and Wilson [14] showed that racing speed on turf surfaces is limited by maximal limb force production when negotiating larger radius turns while tighter turn radii (less than $30 \mathrm{~m}$ ) are traction limited. The traction limits would be related to the hoof surface interaction which would also be expected to be different based on the type of design used for the dirt track [33]. If galloping mechanics on tighter turns follow the same patterns seen in trotting and cantering on small circles, then although the vertical impulses between forelimbs are similar [17], the stance phase is shorter for the outside forelimb [17,34] and centripetal, propulsive and vertical forces are larger [34]. As such, higher forces and loading rates would be predicted for the outside forelimb on tighter turns at gallop, which could, in part, explain why the higher risk of fracture in the left forelimb is no longer significant on turns with the tightest quartile of radii, but was a significantly greater risk in the right forelimb for the two shorter turn radius categories compared to the reference.

On large radius turns where higher speeds are possible, speed in the turns may be limited by the ability to generate vertical ground reaction forces in each limb to support body weight [35]. When galloping on the straight, a higher speed is associated with higher peak vertical force and vertical impulse in both hind limbs, as they carry a greater proportion of body weight [5]. This effect is greater in the trailing hindlimb, which also contributes a larger proportion of propulsive impulse [5]. On tight turns at canter, similar inside to outside forelimb effects appear to be evident in the hindlimb [36]. So, on a larger turn, the right hindlimb may be at greater risk of fatal fractures, as the increased outside limb turning force requirements in addition to trailing limb vertical and propulsive force requirements when negotiating the turn at higher speeds may overload the limb. Turning speed was not considered in this analysis but would be a valuable addition to the knowledge of risk factors in racing and could influence track design in the future. In addition, banking was not evaluated as a factor in our study, which has an influence on turning mechanics [11] because reliable data on the banking of different tracks were not available. In general, the effect of turn radius appears to be small and whatever effect may exist results in differences between the hind limb and forelimb in a manner that may counterbalance the effect of higher loading due to tighter radii and more time spent in turning due to longer turns. In contrast, the effect of forelimb and hind limb function becomes more important when considering the effect of track surfaces.

\subsection{Effect of Surface Material}

The type of surface is important as a determinant of the horse's ability to generate traction which is one of the factors that limits turning speed [14]. If sufficient traction is available, the maximum power produced by all of the limbs can be transferred to the ground. The shear strength of the surface determines the amount of grip and traction. It is higher on synthetic surfaces [1]. The adaptions of the forelimb for weight support and control of speed and direction distinguish it from the power generation adaption of the hind limbs [14]. The effect on forelimb and hindlimb injuries is evident in the significantly higher incidence of forelimb fractures regardless of surface (Table 5). However, the absence of significant left-right asymmetry in fracture rates for any surfaces except dirt may also provide insight into the availability of the traction required for turning on the different surfaces (Figure 1). Given the different functions and significantly lower likelihood of fatal fracture of the hind limbs, the relative risk of left and right limb fractures is considered separately for the forelimbs and hind limbs.

\subsubsection{Forelimb}

Significantly more fatal fractures occur in the forelimbs regardless of the type of surface. However, racing on either turf or synthetic surfaces reduces fatal forelimb fractures alone or 
in combination with other limbs. Since hoof accelerations and peak ground reaction forces are lower on synthetic and turf surfaces [37], it is reasonable to expect that the vertical response of the surface is important. At gallop, the shift in vertical force distribution to support body weight between fore and hindlimbs, which is reported to be $50: 50$ at $19 \mathrm{~m}$ per second, may be necessary to remain within limb force limits [5]. At higher race speeds, vertical impulses must be sufficiently high to support body weight, otherwise the horse must slow down to avoid injury. As stance times are increasingly shorter with increasing speed [38], vertical forces must be higher to produce the required impulse [5]. Another forehindlimb difference relates to the orientation of force vector, as the forelimbs predominantly provide braking, whilst the hindlimbs provide propulsion. During galloping the limbs must redirect the center of mass $(\mathrm{COM})$ from downwards and forwards to upwards and forwards. For the trailing forelimb, the COM has a flatter trajectory during its collision with the surface. For the leading forelimb, the braking and vertical impulses are used to decelerate the COM and provide it with sufficient upward vertical velocity for the flight phase of the stride [39]. This requires a greater braking impulse, which has been found, but was not tested for significance [5]. Energy and forward momentum are lost during this collision, which must be replaced if speed is to be maintained and may contribute to the onset of fatigue.

Energy losses due to surface type are also important when considering fatigue. Greater energy expenditure may be required to maintain speed on some surfaces, which in the forelimb may fatigue the deep digital flexor muscle, compromising the suspensory system [27]. Although this has been indicated as a potential cause of superficial digital tendon rupture [27], compromised soft tissue support may also result in skeletal overload. Given that lead changes occur during races in order to reduce fatigue $[7,8]$, documenting the number of lead changes during races could assist in determining whether fatigue effects are more prevalent on particular surface types. This could help to explain the higher incidence of left forelimb fractures, although knowing preferential leads in training may also be important. Overall, while general observations about the differences in surface response can be made, even the properties of the more consistent synthetic surfaces are influenced by temperature and maintenance [3].

\subsubsection{Hind Limb}

Only the rate of fatal left hind limb fractures is significantly different between surface types with risk ratios as high as 1.74 for the left hind limb on turf. A general trend exists toward higher fatal fracture rates for the hind limbs on both synthetic and turf surfaces, but the effect is only significant for the left hind limb. However, the left-right asymmetry of hind limb fractures is only significant on dirt with an increased incidence in the right hindlimb. The role of the hind limbs in providing tractive forces has been established [5,40]. A synthetic surface has higher shear strength [1] which supports higher craniocaudal loading. While comparable data are not available for turf, it is reasonable to assume that the shear strength of turf may be even higher than synthetic surfaces in which the fibers are randomly oriented. In contrast, the root system in turf is preferentially oriented in the vertical direction which increases the shear strength of the surface in the horizontal axis and this provides better traction during propulsion or turning while allowing the hoof to penetrate the surface.

The ability of turf to support higher craniocaudal loading is likely to be a primary factor in the higher incidence of hind limb fractures on this surface. The greater overall incidence on dirt in the right compared to the left hindlimb may relate to the increased loading on the outside hindlimb in the turn, as discussed previously.

\section{Conclusions}

This study has evaluated injury data for Thoroughbred horses racing on dirt, turf, and synthetic surfaces in relation to the risk of fatal limb fracture which was found to be lowest on a synthetic surface and highest on dirt. A small but in some cases significant 
contralateral limb effect exists for larger turn radii on the dirt surfaces with a higher risk ratio for the right hind and left forelimb. No significant difference in the fractures on the left and right side are evident for the tightest quartile of turn radii considered, turns with radii greater than $50 \mathrm{~m}$ and less than $114 \mathrm{~m}$. Hind limb differences between the left and right are only significant for the largest quartile of radius. Banking in the turns may also be a factor as well as speed of the horse in the turns and should be considered in future studies.

Differences in injury rates by limb on different surfaces are potentially important. Fatal fractures in the hind limbs, while overall much less common than forelimb fractures, may be more common on surfaces with better traction. Understanding the risk of fracture in the right and left limbs on higher traction surfaces like turf and synthetic is a subject worthy of further investigation. With better understanding of limb loading on the different types of surfaces it may be possible to optimize the surfaces for balanced loading across all limbs. Based on the findings presented here, it is clear loading in the horizontal plane must be considered in addition to vertical loading in order to fully understand the interaction of the hoof and ground.

Author Contributions: Conceptualization, M.P., S.J.H. and H.M.C.; methodology, M.P. and M.C.S.; validation, W.S., P.M. and M.C.S.; formal analysis, W.S. and N.K.; writing-original draft preparation, M.P.; writing-review and editing, H.M.C. and S.J.H. All authors have read and agreed to the published version of the manuscript.

Funding: This work was supported in part by a private donation from Bill Casner. Data and additional support were provided by the Jockey Club and affiliated organizations and by the nonprofit Racing Surfaces Testing Laboratory.

Institutional Review Board Statement: Not Applicable.

Informed Consent Statement: Not Applicable.

Data Availability Statement: Data was obtained from The Jockey Club [26]. Restrictions apply to the availability of the data.

Acknowledgments: Data cleaning and validation was performed by Peggy McKee, Kaleb Dempsey and John Peterson of the Racing Surfaces Testing Laboratory. Data interpretation and assistance in the coordination of data sources was provided by Kristin Werner and Matt Iuliano of The Jockey Club. The horse turning figure was drawn by Becky Woodward.

Conflicts of Interest: The authors declare no conflict of interest.

\section{References}

1. Mahaffey, C.A.; Peterson, M.L.; Thomason, J.J.; McIlwraith, C.W. Dynamic Testing of Horseshoe Designs at Impact on Synthetic and Dirt Thoroughbred Racetrack Materials. Equine Vet. J. 2016, 48, 97. [CrossRef] [PubMed]

2. Mahaffey, C.A.; Peterson, M.L.; Roepstorff, L. The Effects of Varying Cushion Depth on Dynamic Loading in Shallow Sand Thoroughbred Horse Dirt Racetracks. Biosyst. Eng. 2013, 114, 178. [CrossRef]

3. Peterson, M.L.; Reiser, R.F.; Kuo, P.H.; Radford, D.W.; McIlwraith, C.W.; Ii, R.F.R.; Kuo, P.H.; Radford, D.W.; Ilwraith, C.W.M.C. Effect of Temperature on Race Times on a Synthetic Surface. Equine Vet. J. 2010, 42, 351. [CrossRef] [PubMed]

4. Harris, S.E. Horse Gaits, Balance and Movement; Howell Book House: New York, NY, USA, 1993.

5. Davies, Z.T.S.; Spence, A.J.; Wilson, A.M. Ground Reaction Forces of Overground Galloping in Ridden Thoroughbred Racehorses. J. Exp. Biol. 2019, 222, jeb204107. [CrossRef] [PubMed]

6. Clayton, H.; Starke, S.; Merritt, J. Individual Limb Contributions to Centripetal Force Generation during Circular Trot. Equine Vet. J. 2014, 46, 38. [CrossRef]

7. Hildebrand, M. The Mechanics of Horse Legs. Am. Sci. 1987, 75, 594.

8. Williams, D.E.; Norris, B.J. Laterality in Stride Pattern Preferences in Racehorses. Anim. Behav. 2007, 74, 941. [CrossRef]

9. Hill, W.T. Survey of Injuries in Thoroughbreds at the New York Racing Association Tracks. Clin. Tech. Equine Pract. 2003, 2, 323. [CrossRef]

10. Schneider, R.K.; Bramlage, L.R.; Gabel, A.A.; Barone, L.M.; Kantrowitz, B.M. Incidence, Location and Classification of 371 Third Carpal Bone Fractures in 313 Horses. Equine Vet. J. 1988, 20, 33. [CrossRef] [PubMed]

11. Hobbs, S.J.; Licka, T.; Polman, R. The Difference in Kinematics of Horses Walking, Trotting and Cantering on a Flat and Banked 10 m Circle. Equine Vet. J. 2011, 43, 686. [CrossRef] 
12. Fredricson, I.; Dalin, G.; Drevemo, S.; Hjerten, G.; Alm, L.O. A Biotechnical Approach to the Geometric Design of Racetracks. Equine Vet. J. 1975, 7, 91. [CrossRef]

13. Fredricson, I.; Dalin, G.; Drevemo, S.; Hjerten, G.; Nilsson, G.; Alm, L.O. Ergonomic Aspects of Poor Racetrack Design. Equine Vet. J. 1975, 7, 63. [CrossRef]

14. Tan, H.; Wilson, A.M. Grip and Limb Force Limits to Turning Performance in Competition Horses. Proc. R. Soc. B Biol. Sci. 2011, 278, 2105. [CrossRef] [PubMed]

15. Chang, Y.-H.H.; Kram, R. Limitations to Maximum Running Speed on Flat Curves. J. Exp. Biol. 2007, 210, 971. [CrossRef] [PubMed]

16. Weyand, P.G.; Sternlight, D.B.; Bellizzi, M.J.; Wright, S. Faster Top Running Speeds Are Achieved with Greater Ground Forces Not More Rapid Leg Movements. J. Appl. Physiol. 2000, 89, 1991. [CrossRef]

17. Chateau, H.; Camus, M.; Holden-Douilly, L.; Falala, S.; Ravary, B.; Vergari, C.; Lepley, J.; Denoix, J.M.; Pourcelot, P.; CrevierDenoix, N. Kinetics of the Forelimb in Horses Circling on Different Ground Surfaces at the Trot. Vet. J. 2013, 198, e20-e26. [CrossRef]

18. Estberg, L.; Stover, S.M.; Gardner, I.A.; Johnson, B.J.; Case, J.T.; Ardans, A.; Read, D.H.; Anderson, M.L.; Barr, B.C.; Daft, B.M.; et al. Fatal Musculoskeletal Injuries Incurred during Racing and Training in Thoroughbreds. J. Am. Vet. Med. Assoc. 1996, 208, 92-96.

19. Mundy, G. Review of Risk Factors Associated with Racing Injuries. In Proceedings of the Annual Convention of the AAEP, Phoenix, AZ, USA, 7-10 December 1997; Volume 43.

20. Peloso, J.G.; Mundy, G.D.; Cohen, N.D. Prevalence of and Factors Associated with Musculoskeletal Racing Injuries of Thoroughbreds. J. Am. Vet. Med. Assoc. 1994, 204, 620.

21. Georgopoulos, S.P.; Parkin, T.D.H. Risk Factors for Equine Fractures in Thoroughbred Flat Racing in North America. Prev. Vet. Med. 2017, 139, 99. [CrossRef]

22. Evans, D.L. Welfare of the Racehorse during Exercise Training and Racing. In The Welfare of Horses; Springer: Berlin/Heidelberg, Germany, 2006.

23. Ueda, Y.; Yoshida, K.; Oikawa, M. Analyses of Race Accident Conditions through Use of Patrol Video. J. Equine Vet. Sci. 1993, 13, 707. [CrossRef]

24. Georgopoulos, S.P.; Parkin, T.D.H. Risk Factors Associated with Fatal Injuries in Thoroughbred Racehorses Competing in Flat Racing in the United States and Canada. J. Am. Vet. Med. Assoc. 2016, 249, 931. [CrossRef] [PubMed]

25. Hitchens, P.L.; Morrice-West, A.V.; Stevenson, M.A.; Whitton, R.C. Meta-Analysis of Risk Factors for Racehorse Catastrophic Musculoskeletal Injury in Flat Racing. Vet. J. 2019, 245, 29. [CrossRef] [PubMed]

26. The Jockey Club. The Jockey Club Releases Data from the Equine Injury Database for 2019. 20 March 2020. Available online: http://jockeyclub.com/pdfs/eid_11_year_tables.pdf (accessed on 8 December 2020).

27. Butcher, M.T.; Hermanson, J.W.; Ducharme, N.G.; Mitchell, L.M.; Soderholm, L.V.; Bertram, J.E.A. Superficial Digital Flexor Tendon Lesions in Racehorses as a Sequela to Muscle Fatigue: A Preliminary Study. Equine Vet. J. 2007, 39, 540. [CrossRef] [PubMed]

28. Mukai, K.; Takahashi, T.; Hada, T.; Eto, D.; Kusano, K.; Yokota, S.; Hiraga, A.; Ishida, N. Influence of Gender and Racing Performance on Heart Rates during Submaximal Exercise in Thoroughbred Racehorses. J. Equine Sci. 2003, 14, 93. [CrossRef]

29. Clayton, H.M.; Lanovaz, J.L.; Schamhardt, H.C.; van Wessum, R. The Effects of a Rider's Mass on Ground Reaction Forces and Fetlock Kinematics at the Trot. Equine Vet. J. 1999, 31, 218. [CrossRef]

30. Hildebrand, M. Motions of the Running Cheetah and Horse. J. Mamal. 1959, 40, 481. [CrossRef]

31. Byström, A.; Clayton, H.M.; Hernlund, E.; Rhodin, M.; Egenvall, A. Equestrian and Biomechanical Perspectives on Laterality in the Horse. Comp. Exerc. Physiol. 2020, 16, 35. [CrossRef]

32. Cully, P.; Nielsen, B.; Lancaster, B.; Martin, J.; McGreevy, P. The Laterality of the Gallop Gait in Thoroughbred Racehorses. PLoS ONE 2018, 13, e0198545. [CrossRef]

33. Mahaffey, C.A.; Peterson, M.; McIlwraith, C.W. Archetypes in Thoroughbred Dirt Racetracks Regarding Track Design, Clay Mineralogy, and Climate. Sports Eng. 2012, 15, 21. [CrossRef]

34. Crevier-Denoix, N.; Camus, M.; Falala, S.; Ravary-Plumioen, B.; Pauchard, M.; Martino, J.; Desquilbet, L.; Chateau, H.; Pourcelot, P. 3D Measurement of the Displacement of the Forelimb Hoof during Stance in Three Horses Circling at the Canter on a Competition Surface. Comput. Methods Biomech. Biomed. Eng. 2014, 17, 142. [CrossRef]

35. Hudson, P.E.; Corr, S.A.; Wilson, A.M. High Speed Galloping in the Cheetah (Acinonyx Jubatus) and the Racing Greyhound (Canis Familiaris): Spatio-Temporal and Kinetic Characteristics. J. Exp. Biol. 2012, 215, 2425. [CrossRef]

36. Crevier-Denoix, N.; Munoz-Nates, F.; Camus, M.; Ravary-Plumioen, B.; Denoix, J.M.; Pourcelot, P.; Chateau, H. Comparison of Peak Vertical Force and Vertical Impulse in the inside and Outside Hind Limbs in Horses Circling on a Soft Surface, at Trot and Canter. Comput. Methods Biomech. Biomed. Eng. 2017, 20, 51. [CrossRef] [PubMed]

37. Setterbo, J.J.; Garcia, T.C.; Campbell, I.P.; Reese, J.L.; Morgan, J.M.; Kim, S.Y.; Hubbard, M.; Stover, S.M. Hoof Accelerations and Ground Reaction Forces of Thoroughbred Racehorses Measured on Dirt, Synthetic, and Turf Track Surfaces. Am. J. Vet. Res. 2009, 70, 1220-1229. [CrossRef] [PubMed]

38. Witte, T.H.; Hirst, C.V.; Wilson, A.M. Effect of Speed on Stride Parameters in Racehorses at Gallop in Field Conditions. J. Exp. Biol. 2006, 209, 4389. [CrossRef] [PubMed] 
39. Bertram, J.E.A.; Gutmann, A. Motions of the Running Horse and Cheetah Revisited: Fundamental Mechanics of the Transverse and Rotary Gallop. J. R. Soc. Interface 2009, 6, 549. [CrossRef] [PubMed]

40. Biewener, A.A. Animal Locomotion; Oxford University Press: Oxford, UK, 2003. 